Philologica Canariensia 22 (2016), 43-54 eISSN: 2386-8635

Recibido: 1 de abril de 2016; versión revisada aceptada: 28 de junio de 2016

Publicado: 25 de octubre de 2016

DOI: 10.20420/PhilCan.2016.102

\title{
LOS SABERES QUE TARJA JOSÉ WATANABE. CONSIDERACIONES EN TORNO A ALGUNOS MOMENTOS DE SU POESÍA
}

\author{
ASUNCIÓN DEL CARMEN RANGEL LÓPEZ \\ Universidad de Guanajuato
}

RESUMEN: Este artículo sienta las bases de una investigación de largo recorrido en donde se postula la siguiente hipótesis: el sujeto que habita en los poemas del peruano José Watanabe es un sujeto que confecciona saberes a través de elementos que están fuera del marco de la escritura, es decir, los consejos y las pequeñas historias de la familia o de la comunidad, lo que habita y surge - para decirlo con uno de sus versos- "en la honda boca de los mayores". Otro aspecto que se analiza en este artículo es la manera en que Watanabe conoce el mundo y, sobre todo, el mundo que inaugura su palabra, la cual involucra una dimensión de la experiencia constantemente contrapuesta y confrontada con ciertos saberes que pertenecen al marco de la escritura, como la física, la matemática, la lingüística o la medicina. El tipo de sujeto que habita en los poemas de Watanabe se encuentra en las antípodas de esta forma de conocimiento; la sapiencia que en su poesía se transmite depende de la propia experiencia del sujeto y de lo que bulle desde "la honda boca de los mayores".

PALABRAS CLAVE: poesía peruana, poesía y experiencia, escritura, parábola, consejo

The knowledge José Watanabe builds.

Considerations regarding some moments in his poetry

ABSTRACT: This article lays the foundation for a long-term research which postulates the following hypothesis: the subject who dwells in the poems by the Peruvian poet Jose Watanabe is one that manufactures knowledge through elements found outside of the writing framework, i.e., pieces of advice and the family or community short stories, that which inhabits in, and arises from-to put it in one of his verses- "the deep mouth of the eldest". This article also addresses Watanabe's way of understanding the world, especially the world opened through his word, which involves a dimension of experience that constantly stands in opposition to certain types of knowledge, for example, physics, mathematics, linguistics, or medicine. The subject who dwells in Watanabe's poems is at the antipodes of this kind of knowledge. The wisdom transmitted through his poetry depends on both the personal experience of the subject and that which comes out from "the deep mouth of the eldest".

KEYWORDS: Peruvian poetry, poetry and experience, writing, parable, advice 


\section{INTRODUCCIÓN}

Quien escribe "con una pregunta obsesiva en las orejas" (v. 3) está condenado, como indica José Watanabe en el poema "Los versos que tarjo", a experimentar en hondura la desazón y la inseguridad. Estos sentimientos se irradian a lo largo de los treinta y seis poemas $-\mathrm{y}$ probablemente en toda su obra escrita en verso- que conforman El huso de la palabra, publicado en Lima en 1989. Dividido en tres momentos, "El amor y no", "Lo mismo la palabra" y "Krankenhaus" (en alemán, 'clínica'), El huso de la palabra da cuenta, desde su inicio, de una serie de particularidades textuales que van adentrando al lector en el sistema de pensamiento de José Watanabe.

Sin embargo, no es solo la dimensión técnica o la pura textualidad - cómo urde y construye sus poemas- el asunto que me interesa comentar en las siguientes páginas. Para alcanzar a atisbar y describir la manera en que el poeta originario de Laredo, Perú, entiende la poesía y qué sucede cuando se escribe poéticamente, considero necesario echar mano de algunas preguntas que se hacía el poeta inglés W. H. Auden cuando leía poesía:

En una memorable conferencia del año 1948, el poeta inglés W. H. Auden, recién fallecido este año, al esbozar su concepción de la poesía y de lo que creía primordial en la relación del hombre con la palabra en nuestra época, anotaba a modo de conclusión: "Las cosas que me interesan al leer un poema son dos: la primera es técnica: he aquí un aparato verbal, ¿̇cómo funciona? La segunda es, en un sentido amplio, moral: ¿̇qué especie de tipo habita este poema? ¿Qué le oculta al lector, qué se oculta a sí mismo?” Cierto, otros intereses pueden concurrir en el ánimo del lector, por ejemplo: ¿qué mundo inaugura esta palabra? ¿Desde cuál zona sensible emprende su captación del universo? ¿Se trata de una alta poesía que se propone áreas estéticas limitadas o, a la inversa, es una poesía fatalmente menor, atrapada en la imposibilidad de ambiciones absolutas? ¿Cuáles ecos prolonga, cuáles apenas enuncia como posibles de ser retomados más tarde? De muchas otras indagaciones, intuitivas o sistemáticas, podemos valernos a la hora de encarar el poema. Conviene sin embargo advertir que las dos apuntadas por Auden se encuentran entre las más esenciales. (Montejo, 2006, 247)

En esta reflexión, perteneciente a un artículo escrito en 1973 por el venezolano Eugenio Montejo sobre la poesía de Drummond de Andrade, Auden enuncia y describe dos momentos cruciales en la lectura de la poesía: primero, ¿cómo funciona el poema, cómo está hecho, cómo está escrito?; y, segundo, y el que quiero destacar para encaminar una ruta de lectura por algunos momentos de la poesía de Watanabe, ¿qué especie de tipo habita ese poema?

El tipo que habita en los poemas de José Watanabe es un sujeto que confecciona saberes a través de elementos que están fuera del marco de la escritura. Esos saberes son los consejos y las pequeñas historias de la familia o de la comunidad, lo que habita y surge - para decirlo con uno de sus versos - "en la honda boca de los mayores" ("El nieto", v. 16). ${ }^{1}$ Asimismo, la manera en que Watanabe conoce el mundo y, sobre todo, el mundo que inaugura su palabra involucran una dimensión de la experiencia constantemente contrapuesta y confrontada con ciertos saberes que pertenecen al marco de la escritura: la física, la matemática, la lingüística, la medicina, en fin, una serie de escrituras que ponen de manifiesto una sabiduría conquistada. El tipo de sujeto que habita en los poemas de Watanabe se encuentra en las antípodas de esta 
forma de conocimiento; la sapiencia que en su poesía se transmite depende de la propia experiencia del sujeto y de lo que bulle desde "la honda boca de los mayores".

En las siguientes páginas, me ocuparé de describir y problematizar esas dos maneras en que discurren sus saberes: primero, el que concierne a "la honda boca de los mayores", y, segundo, el relacionado con la contraposición y pugna constante entre los conocimientos característicos del marco de la escritura. Este conflicto tiene como corolario la referencia a una dimensión de la experiencia que el poeta no puede nombrar a cabalidad.

\section{2. "EN LA HONDA BOCA DE LOS MAYORES"}

El título del poemario El huso de la palabra recibe al lector con el elocuente sustantivo "huso". Se trata de un instrumento manual, nos indica la RAE, de madera, largo, que va adelgazándose desde el medio hacia las dos puntas; sirve para unir y retorcer dos o más hilos. Esta información ayuda a advertir, desde el inicio, que el trabajo poético es el de un artesano, el del poeta que no es "un pequeño dios", como postulaba Vicente Huidobro en el emblemático manifiesto "Non serviam", leído en 1914 en el Ateneo de Santiago de Chile. ${ }^{2}$ El entramado poético se entiende como la unión y retorcedura de hilos que hacen las veces de los poemas contenidos en El huso de la palabra. Entender los versos como una suerte de ensortijamiento genera, no solo para el lector sino para el sujeto que habita en el poema, esa experiencia de desazón e inestabilidad, de vacilación ante lo que va urdiendo, hilo tras hilo, verso tras verso. Me permitiré decirlo de la siguiente manera: pareciera que el sujeto que habita en esa escritura, conforme va hilando sus versos, se permite dudar acerca del estatus que adquieren sus propios poemas. La duda acerca de si lo que realmente se está escribiendo es un poema o si alcanza a ser poesía es, en efecto, una característica de lo que podemos considerar poesía moderna; 3 en Watanabe, esa vacilación tiene un cariz muy particular, por su manera de construirla, de urdirla. Así, por ejemplo, el poema citado al inicio de este artículo, titulado "Los versos que tarjo", se cierra de la siguiente manera: "Los versos que irreprimiblemente tarjo / se llevarán siempre mi poema" (vv. 17-18).

La conciencia de la imposibilidad de aprehender el poema, pese a haberlo escrito, descuella en este texto luego de que el sujeto poemático nos ha presentado una conjetura que pone en cuestión a lo largo del poema a través de mecanismos argumentativos como la afirmación, la pregunta, el símil y, además, una suerte de consejo - muy cercano a la enseñanza que brinda la parábola, aunque no se ajuste a su forma narrativa:

Las palabras no nos reflejan como los espejos, así exactamente, pero quisiera.

Escribo con una pregunta obsesiva en las orejas:

¿Es esta la palabra exacta o el amague de otra que viene

no más bella sino más especular?

Por esta inseguridad

tarjo,

toda la noche tarjo, y en el espejo que aún porfío

sólo queda una figura borrosa, mutilada, malograda. (vv. 1-10)

Philologica Canariensia 22 (2016), 43-54 eISSN: 2386-8635 
Las afirmaciones de los tres primeros versos - sobre la imposibilidad de las palabras, y del deseo vertido en la actividad escritural acerca de la tarea de la palabra, como un reflejo cabal- serán escudriñadas en los versos del cuarto al catorce. El primer momento del poema lo constituye la pregunta por la "palabra exacta" y por la palabra "que viene", la cual no será "más bella sino más especular". Se trata de una interrogación retórica que reafirma que "las palabras no nos reflejan como los espejos" y que reafirma también el deseo del sujeto poemático por conseguir ese reflejo. La tarea que, incansable e inseguramente, ejecutará aparece descrita en los siguientes versos a propósito de "tarjar". Nuevamente, como se vio en el caso del "huso", Watanabe emplea un término que distingue su escritura poética. En este poema se pone en circulación otro vocablo para referirse al afanoso trabajo del artesano -que es el poeta. Quien escribe, en el sistema de pensamiento poético del peruano, emplea el huso para urdir versos y, además, tarja o tacha lo ya escrito para que no sea legible. Del verso siete al diez, la voz poemática dará cuenta de esas vicisitudes y se referirá a lo que queda de su afanoso y nocturno trabajo: "sólo queda una figura borrosa, mutilada, malograda". En efecto, la "amenaza de la madre / sibilina" (vv. 11-12) se cumple: "Tanto te miras en el espejo / que un día terminarás por no verte” (vv. 15-16). En la recuperación de ese consejo que la madre da al niño curioso mirándose al espejo, encontramos un saber que pertenece a la oralidad, que está fuera del marco de la escritura. Ahí, además, se revela lo que Watanabe entiende por escribir, poéticamente hablando: el artesano - el poeta- debe, o debería, volver a poner en circulación el consejo que encarna la parábola para que se cumpla, como se verá más adelante en el comentario del poema "Razón de las parábolas", el ansia de "aquella pequeña historia": "ser de todos" (vv. 6-7). El consejo de la madre pone en circulación una suerte de enseñanza que el artesano recuerda en el momento de la escritura. La amenaza de la madre sibilina, o vaticinio en este caso, se cumple cuando el sujeto poemático tarja para encontrarse tan sólo con "una figura borrosa, mutilada, malograda”, lo cual tendrá, como natural consecuencia, que los versos se lleven siempre su poema.

En esta línea, considero significativo aludir al comentario de Víctor Vich en "El materialismo 'real' de José Watanabe”. En este ensayo, Vich indica que

la mirada de Watanabe es también una mirada política que siempre lo hace dudar de su propia actividad poética. La mirada se presenta como un ejercicio que revela nuevas dimensiones de la realidad cotidiana y de ahí que su poesía (como el haikú) privilegie la visión a la idea: su mirada abre al sujeto hacia nuevas posibilidades y lo sitúa en el medio de un estado de permanente crítica y de duda. $(2010,130)$

En efecto, el estado permanente de crítica y de duda permea en su totalidad la obra de Watanabe; son diversos los momentos en que escribe sobre su ríspida relación con el lenguaje, con la palabra. ${ }^{4}$ Asimismo, se privilegia la visión sobre la idea, como se nota en "Los versos que tarjo", una cosa es el deseo y el afanoso trabajo de hacer empatar la palabra con el reflejo y otra muy distinta es lo que la realidad escritural le deja: "una figura borrosa, mutilada, malograda". Ahora bien, estos presupuestos poéticos revelan "nuevas dimensiones de la realidad cotidiana"; se trata de un mundo que inaugura su palabra en el que será vital la recuperación de una forma discursiva de antiquísimo abolengo: la amenaza que, en el contexto del poema, 
funciona como consejo o parábola. La madre sibilina, recuerda el sujeto poemático, le había dicho en su infancia: “Tantas veces te miras al espejo / que un día terminarás por no verte”. Este no será el único momento en que en la poesía de Watanabe aparezca la voz del otro, la vieja palabra con poderes casi proféticos.

En "Razón de las parábolas”, un poema del libro Habitó entre nosotros” (2002), el poeta de Laredo nos presenta, no una de las faces de su intrincada y ríspida relación con las palabras que no pueden ser espejo, pero que desea que así fueran, sino, muy por el contrario, otra relación que guarda con la palabra en cuanto a su capacidad de transmitir - no de inventar- de hacer llegar a quien escucha - no solo a quien lee- un consejo. En el fondo de esta manera de concebir la palabra, Watanabe pone de manifiesto que la sabiduría no es algo que se conquista, sino algo que se aprehende a través y gracias al cedazo de la experiencia que posibilita la transmisión de un consejo. 5 En un primer momento del poema leemos:

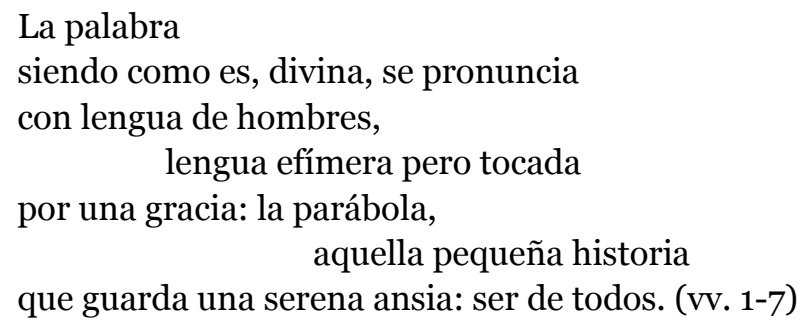

Tenemos a la vista dos rasgos de la palabra: primero, que corresponde a una esfera "divina" $-\mathrm{y}$, por tanto, privilegio de los dioses-y, segundo, que cede en esa perfección celestial para ser objeto de la lengua de los hombres. Efímera, en su dimensión humana y telúrica, conserva una gracia: ser una "pequeña historia" para todos. Hay aquí un profundo sentimiento cristiano en su acepción más simple y primigenia: el amor por el prójimo y la bondad. Si consideramos la parábola como una suerte de relato que tiene una significación moral, filosófica y/o religiosa, esta enseñanza busca, no la conquista de la sabiduría, sino llegar a ser escuchada por todos, a ser de todos, como muestra de una contundente generosidad.

El siguiente momento del poema encierra una sugerente relación entre la palabra como espacio de transmisión de un consejo - una vivencia o una experiencia- e hilar, o emplear el huso para la costura o construcción del verso: "Por eso hablo así, hilando / La Palabra en vides, en semillas de mostaza" (vv. 8-9). Resulta significativa la elección del verbo "hablar”, y no del verbo "escribir", si se trata, precisamente, de la operación que tendrá como natural consecuencia la escritura de un poema. Predomina aquí, una vez más, esa ponderación que Watanabe hace de la oralidad, de la palabra fuera del marco de la escritura.

Al hablar, el sujeto poemático hila "La Palabra", ensortijando "vides", "semillas de mostaza", "trigo", "cizaña" (vv. 9-11), esto es, una serie de tópicos que corresponden al léxico y campos semánticos inscritos en la Biblia. ${ }^{6}$ Pero, además, al hilar ensortija el "pedregal”: "cosas de la gente / de sus manos" (vv. 11-12). Con estos elementos, Watanabe da cuenta de ese otro mundo que inaugura su palabra poética. La progresión en el ensortijamiento de los tópicos de este poema dedicado a las parábolas permite reparar en un asunto de capital importancia: las parábolas, las pequeñas historias que transmiten consejo, están orientadas a poner de 
manifiesto que no hay una disociación entre la intimidad y el mundo exterior. La progresión de los tópicos del poema se inicia en un asunto de índole divina, para vincularse después, de manera decisiva, a la dimensión telúrica - humana, demasiado humana- de la lengua de los hombres, que busca llegar, por "una serena ansia", a "ser de todos" -la tesis. La segunda parte del poema da cuenta de la injerencia, en diversos órdenes de la vida, del hombre que tiene La Palabra y, por extensión, la parábola -la antítesis. El tercer momento es, sin más, un repliegue a la esfera de lo íntimo -la síntesis. El paso necesario entre los dos primeros momentos hasta llegar al tercero, el de la intimidad, no se disocia o separa del mundo exterior -la tesis y la antítesis.

Llegados aquí, podemos confirmar las siguientes hipótesis a propósito del pensamiento poético de José Watanabe: primero, que el poeta es un artesano que tarja o que emplea el huso en la confección de sus versos; segundo, que siempre dudará sobre si lo que escribe es efectivamente el verso deseado; y, tercero, que un poeta-artesano como Watanabe busca recuperar o volver a poner en circulación - a través de su poesía- el consejo y la dimensión oral que encarna la parábola.

El poema "El nieto", que abre el apartado "Krankenhaus" del poemario El huso de la palabra, contiene el verso "en la honda boca de los mayores" (v. 16), con el que he titulado esta sección. "Krankenhaus" ('clínica' u 'hospital' en alemán) incluye poemas que describen el paso del poeta de Laredo por una serie de procedimientos quirúrgicos y médicos que buscaron atacar el cáncer que padeció, enfermedad por la que murió en 2007. En "El nieto" podemos distinguir dos momentos: el primero se refiere a cómo, al morir el abuelo Don Calixto Varas, una rana emergida de su pecho se convirtió en una palabra. En ese momento del poema, Watanabe da cuenta de esa otra experiencia que no puede nombrar, acerca de la cual no tiene las palabras que siquiera alcancen a decirla:

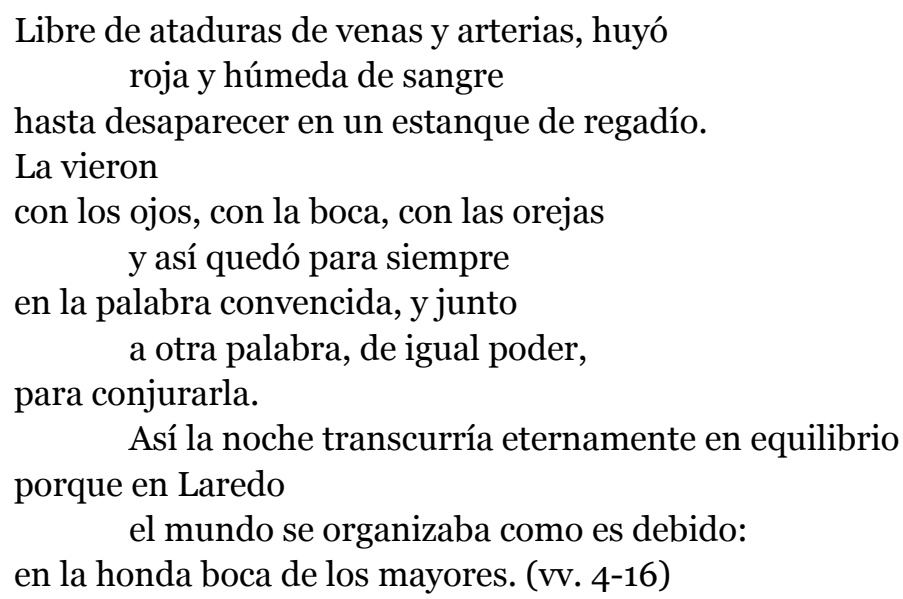

A diferencia del segundo momento del poema, que comentaré a continuación, en los versos arriba citados el sujeto que habita permanece como un observador de lo sucedido, es decir, habla del abuelo, de quienes "vieron" la rana y de los mayores. El hecho de tomar distancia le permitirá llevar a la esfera de lo íntimo la amarga experiencia de la muerte del abuelo - del otro- como se verá más adelante. De este momento de "El nieto" vale la pena reparar en la 
referencia a la rana que se transmuta en una "palabra convencida" y que está junto a "otra palabra, de igual poder, / para conjurarla”. A esto aludo al decir que en Watanabe hay una vivencia o experiencia que no se puede nombrar, por más que el poeta se afane en intentar conseguirlo. ¿Qué palabra es aquella que tiene los atributos de "convencida", de poderosa, que conjura? Ni siquiera es la palabra muerte, que el poeta no tiene empacho en nombrar al inicio del poema. Pareciera que lo que se resiste a nombrar, porque no daría cuenta a cabalidad de lo experimentado, es la agonía. No daría cuenta de esa experiencia porque, como descubrimos en la segunda parte del poema, la agonía no es el natural proceso de la vida hacia la muerte; la agonía sería, más bien, una secreta metamorfosis:

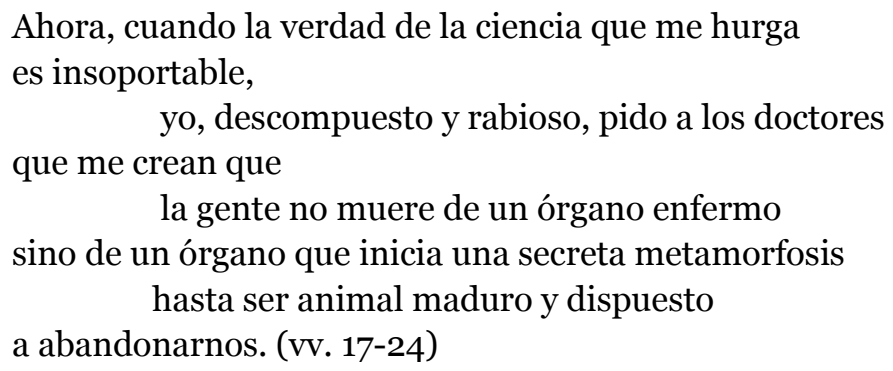

Tenemos aquí un claro contraste entre los saberes de la medicina y lo que habita "en la honda boca de los mayores": no es un órgano enfermo lo que lleva irremediablemente a la muerte; es más, ni siquiera ese sería el punto de recalada. En la enfermedad, lo que el sujeto que ahí habita comienza a experimentar es aquella vivencia que abrevó de la muerte del abuelo: el órgano que a la vista de la medicina está enfermo, visto al trasluz de los saberes bebidos de "la honda boca de los mayores", sería un "animal maduro y dispuesto / a abandonarnos", convertido en rana.

\section{NOLI ME LEGERE}

Para la tradición alquimista, “un libro ‘cerrado’ significa la materia virgen. Si está 'abierto', la materia fecundada. Cerrado, el libro conserva su secreto. Abierto, el contenido es aprehendido por quien lo escruta... Así el gran libro de la naturaleza, que encierra en sus páginas la revelación de las ciencias profanas y de los misterios sagrados" (Chevalier, 2009, 645). La idea de la naturaleza como libro y el libro como naturaleza, apuntada también por Ernest Robert Curtius en Literatura europea y Edad Media latina (1955), es un viejo tópico del que se nutre, a su manera, el Romanticismo alemán temprano (Berlín, 2000; Marí, 1979).

En el apartado "La naturaleza enajenada", del El Héroe y el Único (2008), Rafael Argullol, en su indagación acerca de la escisión que priva en el talante del romántico, señala: "el artista romántico anhela el Uno primordial que ha entrevisto en su gran sueño de totalidad; anhela la geografía sólo existente en su corazón y en su deseo, que hacía de la naturaleza y el ser, del dios y del hombre, una sólida unidad... El hombre, para la razón romántica, se siente escindido consigo mismo: pero la causa esencial de ello es que se halla escindido con respecto a la naturaleza" (2008, 331). De acuerdo con los alquimistas, la naturaleza es algo que se puede leer y, de esta manera, comprender, sentir. Al espíritu del romanticismo le incumbió padecer 
las vicisitudes de encontrarse separado de manera radical de ella y la correspondiente pulsión y gana de volver a ser uno, de emprender la no sencilla y muy dolorosa tarea de encontrar la unidad entre la naturaleza y el ser.

El pensamiento poético de José Watanabe se encuentra en las antípodas de estos presupuestos. A los sujetos que habitan en su poesía la naturaleza parece decirles constantemente noli me legere, y de ahí que esos sujetos recurran una y otra vez a saberes contenidos en el Libro, a conocimientos inscritos en el marco de la escritura. Del conflicto entre lo que la naturaleza parece decirles, pero que no pueden leer y por lo que acuden a, por ejemplo, la enciclopedia en aras de comprender lo que están presenciando, resulta la mención, tan solo la mención, de algo de esa experiencia que apenas pueden nombrar mediante un gesto, una mueca o un guiño. Un ejemplo de ello lo constituye el poema "La mantis religiosa", incluido en el apartado "El amor y no", del ya aludido El huso de la palabra. En el poema, el sujeto lírico se refiere a cómo se encuentra observando - a cincuenta centímetros de sus ojos - una mantis inmóvil: "Yo estaba tendido sobre las piedras calientes de la orilla del / Chanchamayo", se apunta en los versos cuarto y quinto.

El tópico "tendido sobre las piedras" al borde de un río y contemplando -intentando leeralgún aspecto del mundo natural aparecerá constantemente en la obra de Watanabe. Así, por ejemplo, en "Refulge otra vez el sol" se apunta: "siéntate en la hierba con espíritu tranquilo / y mira a los muchachos bañarse y reír" (vv. 2-3). En el poema dedicado a la mantis, el sujeto poemático, además de observar, intenta apresar con su mano esa "imitación de ramita o palito seco" (v. 7). Tras el verso donde se describe la manera de desintegrarse, al tacto, de la mantis religiosa ("se desintegró entre mis dedos como una fina y quebradiza / cáscara", vv. 9-10), viene la referencia, a boca de jarro, a los saberes contenidos en la enciclopedia que, cabe destacar, es quizá la mayor representación de los conocimientos pertenecientes al marco de la escritura. La parte central del poema contiene la poetización de la información proporcionada por esa escritura; se trata de la descripción del coito de la mantis y la manera en que la hembra, en la cópula, lleva al macho a la muerte:

Una enciclopedia casual me explica ahora que yo había destruido

a un macho vacío.

$[\ldots]$

En el beso

ella desliza una larga lengua tubular hasta el estómago de él

y por la lengua le gotea una saliva cáustica, un ácido,

que va licuándole los órganos

y el tejido del más distante vericueto interno, mientras le hace gozo,

y mientras le hace gozo la lengua lo absorbe,

repasando

la extrema gota de sustancia del pie o del seso, y el macho

se continúa así de la suprema esquizofrenia de la cópula

a la muerte.

Y ya viéndolo cáscara, ella vuela, su lengua otra vez lengüita. (vv. 11-13, 21-31) 
En el último momento del poema destaca, de manera análoga a "El nieto", una referencia a ese saber que no proviene de la enciclopedia, sino del enfrentamiento del sujeto poemático con el macho seco y vacío, con la mantis que quiso "atrapar, [y] demostrarle que un ojo siempre nos descubre" (v. 8). El cruce entre los saberes enciclopédicos y aquello que el sujeto lírico busca conocer, esto es, la última palabra "fijada para siempre en la boca abierta y muerta / del macho" (vv. 34-35), es algo que, nuevamente, no podrá ser nombrado por el sujeto que habita en esos versos. Este proceder poético es una constante en la manera de tarjar versos de José Watanabe: el conflicto entre la observación o la posible lectura de algún motivo natural o del mundo en que habita, y el consecuente desfase con la gana de comprender lo postrado ante su inteligencia y sensibilidad a través de los saberes de la enciclopedia o de la medicina, inscritos en el marco de la escritura. Ante ese conflicto, Watanabe acude a otro tipo de conocimientos, de informaciones y saberes que emanan de manera directa de la experiencia de la madre sibilina, de la boca de los mayores o de la vivencia propia -como es el caso de la mantis religiosa- para decirnos, para comunicarnos a través de su poesía, que hay algo que escapa a esta última manera de estar en el mundo, y que aquello que escapa no se puede siquiera nombrar. De ahí que hacia el final de sus poemas, como sucede en "Los versos que tarjo", "El nieto" y "La mantis religiosa", aluda a la palabra. En el caso del último poema, dedicado a la mantis, menciona la palabra "fijada para siempre en la boca abierta y muerta" de la mantis y, luego, a la "palabra / de agradecimiento" que "nosotros no debemos negar" (vv. 36-37). Watanabe esboza el tipo de palabra, pero no la enuncia, como sucede con la palabra convencida y poderosa del poema "El nieto".

Para cerrar estas consideraciones en torno a la poesía del originario de Laredo, voy a referirme a otro momento donde resulta aparente este procedimiento de su pensamiento poético. Se trata de "El anónimo (alguien, antes de Newton)", perteneciente a El huso de la palabra, en el apartado "Lo mismo la palabra". En los primeros versos del poema, el sujeto poemático da cuenta de cómo, al estar en la cornisa de una montaña, deja caer una piedra, y mientras esta cae - "libre y limpia", indica en el verso quinto- experimenta la extrañeza de sentir que la piedra, en realidad, no cae,

sino que baja convocada por la tierra, llamada por un poder invisible e inevitable.

Mi boca quiere nombrar ese poder, hace aspavientos, balbucea y no pronuncia nada. (vv. 7-10)

El título proporciona las informaciones necesarias para descubrir que, conforme se van leyendo los versos, el sujeto poemático se refiere a la ley de gravitación universal enunciada hacia el siglo XVII por Isaac Newton. A efectos de la ruta de lectura que vengo proponiendo a lo largo de estas páginas, sobre el proceder y pensamiento poéticos de Watanabe, los versos relacionados con aquello que se quiere nombrar, pero no es posible hacerlo, ponen de manifiesto que no será el conocimiento contenido en las leyes de gravitación universal lo que acuda en ayuda del sujeto poemático para enunciar aquello que está observando: las razones por las que la piedra "baja convocada por la tierra". 
El remate del poema es ilustrativo respecto de los saberes que no están contenidos en el marco de la escritura, sino que emanan de la experiencia directa del sujeto con el mundo, los saberes que pondera la poesía de José Watanabe:

\author{
Yo me contento con haberlo entrevisto. \\ No tuve el lenguaje y esa falta no me desconsuela, \\ algún día otro hombre, subido en esta montaña, \\ o en otra, \\ dirá más, y con más precisión. \\ Ese hombre, sin saberlo, estará cumpliendo conmigo (vv. 14-19).
}

Es el lenguaje especializado, el de la ciencia, con el que, efectivamente, no contaba el sujeto lírico; pero sí contaba, en ese momento, con la sensibilidad y la disposición temperamental y sentimental para percibir o para entrever lo que deja consignado al inicio del poema, a saber, que la piedra no cae, sino que es llamada por la tierra a través de un poder "invisible e inevitable".

\title{
4. CODA
}

Este breve recorrido por algunos de los momentos de la poesía de Watanabe adolece, sin duda, de la consideración de otros elementos que entran en circulación en la tarea de trazar una ruta de lectura. Los elementos que atañen al cuerpo, por ejemplo, constituyen otros puentes y asideros interpretativos que quedan por indagar. Para terminar, quisiera anotar que, en efecto, la esfera de lo íntimo y de lo público aparece poematizada en la obra de Watanabe y que, en esa operación, los saberes que no se conquistan, sino que se transmiten, como he apuntado a lo largo de estas páginas, juegan un papel crucial. Las cosas del cuerpo, los asuntos del cuerpo, convocan en la poesía de Watanabe ese doloroso proceso que finalmente extinguió su vida; pero, además, convocan otro tipo de saberes que se materializan y objetivan en la escritura, y que apunto aquí como otra propuesta de lectura más en el desarrollo de esta investigación: el cuerpo y sus intimidades no se disocian de la esfera pública y política. La mirada de este poeta, como apunta Vich $(2010,130)$, es siempre de esa índole: política.

\section{NOTAS}

1 Las constantes referencias a lo que está "fuera del marco de la escritura" intentan suscribir una de las fascinantes y sugerentes ideas contenidas en Escribir en el aire (2003) de Antonio Cornejo Polar. En la primera parte de su libro, donde contrapone lo que ideológicamente encarnan el libro y la letra frente a la oralidad y la agrafía - sobre el emblemático "diálogo" de Cajamarca - se refiere a las dinámicas "que provienen de la oralidad y otras impensables fuera del marco de la escritura" (51). Las formas que están fuera del marco de la escritura o en el borde de las mismas son, aquí, el consejo, la parábola y las pequeñas historias.

2 Pablo Neruda, en su discurso al recibir el Premio Nobel de Literatura en 1971, apuntaba: "El poeta no es un 'pequeño dios'. No, no es un 'pequeño dios'. No está signado por un destino cabalístico superior al de quienes ejercen otros menesteres y oficios. A menudo expresé que el mejor poeta es el 
hombre que nos entrega el pan de cada día: el panadero más próximo que no se cree Dios" $(1972,27)$.

3 En Estructura de la lírica moderna (1959), Hugo Friedrich indica que las características de la poesía moderna son: oscuridad, disonancia y antisentimentalismo. En el interior de la poesía, apunta Friedrich, se discute el estatus de la propia escritura, es decir, una escritura que se piensa a sí misma, que discurre sobre sus materiales, sobre su condición, sobre lo que es.

4 Un ejemplo de ello lo encarnan los poemas contenidos en la "Coda" al poemario Historia natural (1994). Me refiero a "De la poesía" y "Arte poética". De este último, obsérvense los primeros versos: "Deja tu alfiler de entomólogo, poeta: / las palabras no son mariposas con teta".

5 Sobre la función de las parábolas - las pequeñas historias, como dijera Watanabe- como una forma idónea de transmisión y consejo, sigo algunas de las líneas de reflexión que provienen del pensamiento de Walter Benjamin, particularmente en sus textos "Experiencia y pobreza" (1933) y El narrador (1952), en donde -apunto grosso modo y siguiendo a Pablo Oyarzún en la introducción- Benjamin pondera el poder de la parábola como vehículo idóneo para la transmisión de un consejo que se brinda a quien está dispuesto a escuchar. El narrador en el que piensa Benjamin no es el de la novela, sino el narrador que transmite lo que va de boca en boca. La capacidad de brindar consejos depende de la validez, indica Benjamin, de la propia experiencia del narrador o de su acrisolada fidelidad a la memoria que conserva lo que transmite. En esta línea, me parece que los sujetos que habitan en los poemas de José Watanabe suelen adquirir ese cariz de dar consejo, como repitiendo fielmente lo que está en la memoria de los mayores, de la madre sibilina.

6 A propósito de Habitó entre nosotros, el mismo Watanabe indica la profunda relación entre ese libro y la Biblia. En entrevista con Diego Molina, apunta: "Nació de un proyecto con el artista plástico Eduardo Tokeshi de coger un cuadro famoso; yo haría un poema y él un grabado. Una noche dio la casualidad de que escribí como seis poemas sobre cuadros religiosos y todos eran sobre etapas de la vida de Cristo, como la resurrección, Lázaro y la Natividad. Entonces dejé las ilustraciones y fui directo a la Biblia" (2003, 95).

\section{REFERENCIAS BIBLIOGRÁFICAS}

ARGULlOL, R. 2008. El Héroe y el Único. El espíritu trágico del Romanticismo. Barcelona: Acantilado. . 2005. “Aventura”. Enciclopedia del crepúsculo. Barcelona: Acantilado, 69-84.

BENJAMIN, W. 2008. El narrador. Oyarzún, P. (introd.). Santiago de Chile: Metales pesados. BERLIN, I. 2000. Las raíces del romanticismo. Madrid: Taurus.

CHEVALIER, J. 1986. Diccionario de los símbolos. Barcelona: Herder.

CHIRINOS, E. 2004. Los largos oficios inservibles. Lima: Norma.

CORNEJO POLAR, A. 2003. Escribir en el aire. Ensayo sobre la heterogeneidad sociocultural en las literaturas andinas. Lima: Latinoamericana.

CURTIUS, E. R. 1955. Literatura europea y Edad Media latina. México: Fondo de Cultura Económica.

DE PAZ, M., 2010. El ombligo en el adobe. Asedios a José Watanabe. Lima: Mesa Redonda.

FERNÁNDEZ COZMÁN, C. 2008. Mito, cuerpo y modernidad en la poesía de José Watanabe. Lima: Cuerpo de la Metáfora. 
FRIEDRICH, H. 1974. Estructura de la lírica moderna. De Baudelaire hasta nuestros días. Barcelona: Seix Barral.

MARÍ, A. 1979. El entusiasmo y la quietud. Antología del romanticismo alemán. Barcelona: Tusquets.

MÉNDEZ, J. C. 2002. “José Watanabe: camino al cielo” (entrevista), Caretas, 19, 86-87.

MOLINA, D. 2003. "La iluminación y la materia. Entrevista con José Watanabe", Ideele, 153, 92-96.

MONTEJO, E. 2006. "Poesía y vitalidad en Drummond de Andrade”, en Castañón, A. (ed.), Geometría de las horas. Una lección antológica. México: Universidad Veracruzana.

NERUDA, P. 1972. "Verdad o poesía”, en Coloane F. (ed.), Obras escogidas, tomo I. Santiago de Chile: Andrés Bello.

NING, J. L., 2014. Cosas de familia. Metáfora de la identidad en la poética de José Watanabe. Lima: Murrup.

TORO MONTALVO, C. 1990. Poesía peruana del 70: generación vanguardista. Lima: La Tortuga Ecuestre.

VICH, V. 2010. "El materialismo 'real' de José Watanabe", Iberoamericana, X (37), 119-134.

WATANABE, J. 2008. Poesía completa. Madrid: Pretextos.

\section{NOTA SOBRE LA AUTORA}

Asunción del Carmen Rangel López es doctora en Letras Mexicanas por la Universidad Nacional Autónoma de México y profesora-investigadora del Departamento de Letras Hispánicas de la Universidad de Guanajuato, México. Es miembro del Sistema Nacional de Investigadores desde enero de 2013. 